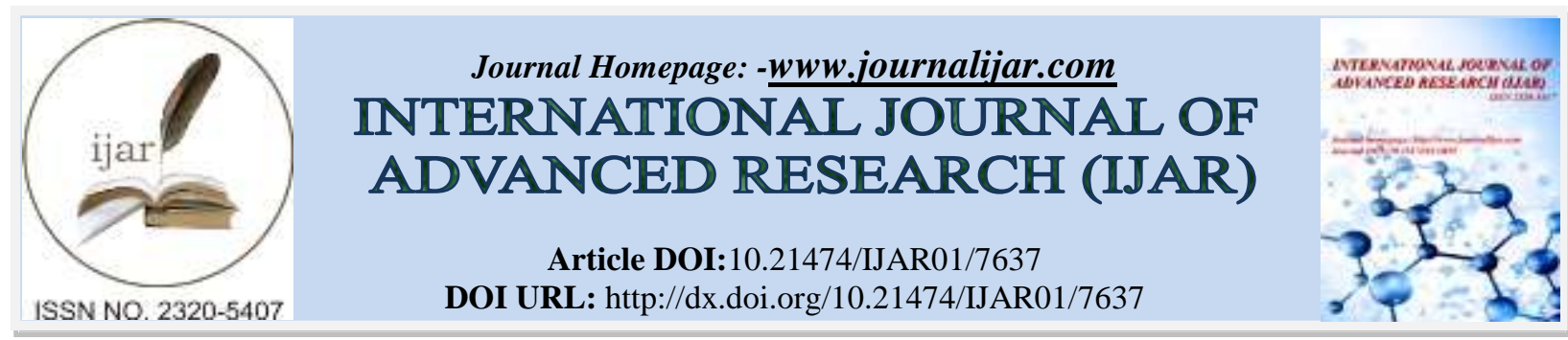

ORIGINAL ARTICLE

\title{
MELASMA AS A STATE MARKER OF PSYCHIATRIC DISORDERS.
}

\author{
Dr. Nidhi Kumar ${ }^{1}$, Dr. Amit Kumar ${ }^{2}$ and Dr. P Sarkar³ . \\ 1. Assistant Professor (Psychiatry), Military Hospital Kirkee, Pune, India. \\ 2. Assistant Professor (Psychiatry), Command Hospital (AF) Bangalore, India. \\ 3. Consultant (Psychiatry), Apollo Gleneagles Hospital, Kolkata, India.
}

\section{Manuscript Info}

Manuscript History

Received: 24 June 2018

Final Accepted: 26 July 2018

Published: August 2018

\section{Abstract}

Copy Right, IJAR, 2018,. All rights reserved.

\section{Introduction:-}

Melasma is a common acquired disorder manifesting in hyperpigmented patches with irregular margins, occurring mostly on face and usually symmetric. It is most commonly seen in young to middle aged women with darker skin phototypes and is rare before puberty ${ }^{1}$. Exacerbating factors as mentioned in literature include pregnancy, oral contraceptives, hormone replacement therapy (HRT) and exposure to sun ${ }^{2}$. In our outpatient psychiatry clinic, we noticed a large number of people having melasma on their faces, which prompted us to study whether there is a higher prevalence of melasma in people with psychiatric disorders compared to general population, and if that be so, which diagnostic categories had higher prevalence. No study has been published about association between melasma and psychiatric disorders, to best of our knowledge.

\section{Methods:-}

All consecutive individuals reported for treatment to out patient psychiatry dept in a tertiary care general hospital psychiatry unit over a period of 45 days were examined for the presence of melasma on their faces and were included in the study after taking their consent. None of the women were pregnant or taking oral contraceptive pills/hormone replacement therapy.

Each individual was interviewed by an experienced psychiatrist and diagnosed as per research criteria for ICD $10^{3}$. The diagnosis was then reviewed by another experienced psychiatrist who interviewed the patient separately. Whenever doubt about diagnosis arose, consensus was achieved after consulting with a third psychiatrist. Presence or absence of melasma was also independently confirmed by two psychiatrists. Simultaneously, prevalence of melasma in age and gender matched people from the local community as control group was obtained by examining their faces. Whether anyone in the control group had psychiatric disorder was not known.

The data thus obtained was entered on Excel spreadsheet and compared using the Statistical Procedures for the Social Sciences (SPSS) version 14.0 for Windows. A non parametrictests (Chi square test) was used for testing the significance of results. 


\section{Results:-}

A total of 328 individuals ( 82 men and 246 women) reported consecutively for treatment during this period of 45 days at our outpatient psychiatry clinic. Out of them, 120 individuals (36.6\%) had melasma on face. Out of 82 men, $26(31.7 \%)$ had melasma and out of 246 women, 94 (38.2\%) had melasma. In comparison, the prevalence of melasma in the age and gender matched control group of 328 individuals was $19(5.8 \%)$ which was significantly lower $\left(\mathrm{x}^{2}=1\right.$, d.f. $\left.=1, \mathrm{p}<0.01\right)$. Melasma was not seen in individuals in the age group of below 15 years in both groups. Barring this age group, prevalence of melasma was higher in patient group compared to control group across age groups and gender. Age, gender and prevalence of melasma in these two groups are depicted in Table 1.

Table I;-Age, gender \& prevalence of Melasma in patient and control groups

\begin{tabular}{|c|c|c|c|c|c|c|}
\hline \multirow{2}{*}{$\begin{array}{l}\text { Age in } \\
\text { years }\end{array}$} & \multirow[t]{2}{*}{ Sex } & \multirow[t]{2}{*}{ Total } & \multicolumn{2}{|c|}{ Control Group } & \multicolumn{2}{|c|}{ Patient Group } \\
\hline & & & $\begin{array}{l}\text { Melasma } \\
\text { present }\end{array}$ & $\begin{array}{l}\% \text { with } \\
\text { Melasma }\end{array}$ & $\begin{array}{c}\text { Melasma } \\
\text { present }\end{array}$ & $\begin{array}{l}\% \text { with } \\
\text { Melasma }\end{array}$ \\
\hline \multirow[t]{3}{*}{$1-15$} & Men & 5 & 0 & 0 & 0 & 0 \\
\hline & Women & 5 & 0 & 0 & 0 & 0 \\
\hline & Total & 10 & 0 & 0 & 0 & 0 \\
\hline \multirow[t]{3}{*}{$16-25$} & Men & 4 & 0 & 0 & 1 & 25 \\
\hline & Women & 9 & 1 & 11.1 & 3 & 33.4 \\
\hline & Total & 13 & 1 & 7.7 & 4 & 30.8 \\
\hline \multirow[t]{3}{*}{$26-35$} & Men & 16 & 1 & 5.3 & 5 & 31.3 \\
\hline & Women & 32 & 3 & 9.5 & 13 & 40.6 \\
\hline & Total & 48 & 4 & 8.3 & 18 & 37.5 \\
\hline \multirow[t]{3}{*}{$36-45$} & Men & 25 & 2 & 8 & 9 & 36 \\
\hline & Women & 78 & 7 & 8.9 & 31 & 39.8 \\
\hline & Total & 103 & 9 & 8.7 & 40 & 38.8 \\
\hline \multirow[t]{3}{*}{$46-55$} & Men & 23 & 1 & 4.3 & 8 & 34.8 \\
\hline & Women & 91 & 2 & 2.2 & 33 & 36.3 \\
\hline & Total & 114 & 3 & 2.6 & 41 & 35.1 \\
\hline \multirow[t]{3}{*}{$56-65$} & Men & 5 & 0 & 0 & 3 & 60 \\
\hline & Women & 26 & 1 & 3.8 & 11 & 42.3 \\
\hline & Total & 31 & 1 & 3.2 & 14 & 45.2 \\
\hline \multirow[t]{3}{*}{$>66$} & Men & 4 & 0 & 0 & 0 & 0 \\
\hline & Women & 5 & 1 & 20 & 3 & 60 \\
\hline & Total & 9 & 1 & 11.1 & 3 & 33.3 \\
\hline
\end{tabular}

Among patient group, the 5 most common diagnoses were generalized anxiety disorder $(25.6 \%, \mathrm{n}=84)$, Mixed anxiety and depressive disorder $(16.2 \%, \mathrm{n}=53)$. Depressive episode $(11.3 \%, \mathrm{n}=37)$, Bipolar affective disorder $(9.4 \%, \mathrm{n}=31)$ and Schizophrenia $(7.9 \%, \mathrm{n}=26)$.

Table 2 depicts the prevalence of various psychiatric disorders in the patient group of study.

Table 2:-Prevalence of psychiatric disorders in the patient groups

\begin{tabular}{|l|l|l|l|}
\hline \multicolumn{1}{|c|}{ Disorder } & Men & Women & \% of Total \\
\hline Generalized Anxiety Disorder (GAD) & 20 & 64 & 25.6 \\
\hline Mixed Anxiety and Depressive Disorder (MADD) & 15 & 38 & 16.2 \\
\hline Depressive Episode (DE) & 4 & 33 & 11.3 \\
\hline Bipolar Affective Disorder (BAD) & 8 & 23 & 9.4 \\
\hline Schizophrenia (SC) & 7 & 19 & 7.9 \\
\hline Other Non Organic Psychotic Disorder (ONOPD) & 5 & 17 & 6.7 \\
\hline Alcohol Dependence Syndrome (ADS) & 17 & 0 & 5.2 \\
\hline Dissociative Disorder (DD) & 2 & 12 & 4.3 \\
\hline Dissociative Disorder (DD) + Depressive Episode (DE) & 0 & 8 & 2.4 \\
\hline Obsessive and Compulsive Disorder (OCD) & 0 & 8 & 2.4 \\
\hline Panic Disorder (PD) & 2 & 5 & 2.1 \\
\hline Somatoform Disorder (SD) & 1 & 5 & 1.8 \\
\hline
\end{tabular}




\begin{tabular}{|l|l|l|l|}
\hline Others & 1 & 14 & 4.6 \\
\hline
\end{tabular}

Diagnoses of individuals in patient group along with distribution and presence of melasma are given in table 3.

Table 3:-Prevalence of Melasma in the patient group diagnoses wise

\begin{tabular}{|l|l|l|l|l|l|l|l|l|l|}
\hline \multirow{2}{*}{ Disorder } & \multicolumn{3}{|c|}{ Men } & \multicolumn{3}{c|}{ Women } & \multicolumn{3}{c|}{ Total } \\
\cline { 2 - 10 } & Total & $\begin{array}{l}\text { Having } \\
\text { Melasma }\end{array}$ & $\begin{array}{l}\text { Melaving } \\
\text { Melaving }\end{array}$ & Total & $\begin{array}{l}\text { Having } \\
\text { Melasma }\end{array}$ & $\begin{array}{l}\text { Total } \\
\text { Melasma }\end{array}$ & $\begin{array}{l}\text { Having } \\
\text { Melasma }\end{array}$ & $\begin{array}{l}\% \text { having } \\
\text { Melasma }\end{array}$ \\
\hline GAD & 20 & 14 & 70 & 64 & 55 & 85.9 & 84 & 69 & 82.1 \\
\hline MADD & 15 & 5 & 33.3 & 38 & 21 & 55.3 & 53 & 26 & 49.1 \\
\hline DE & 4 & 0 & 0 & 33 & 0 & 0 & 37 & 0 & 0 \\
\hline BAD & 8 & 1 & 12.5 & 23 & 0 & 0 & 31 & 1 & 3.2 \\
\hline SC & 7 & 1 & 14.3 & 19 & 3 & 15.8 & 26 & 4 & 15.4 \\
\hline ONOPD & 5 & 1 & 20 & 17 & 2 & 11.8 & 22 & 3 & 13.6 \\
\hline ADS & 17 & 2 & 11.8 & 0 & 0 & 0 & 17 & 2 & 11.8 \\
\hline DD & 2 & 1 & 50 & 12 & 5 & 41.7 & 14 & 6 & 42.9 \\
\hline DD + DE & 0 & 0 & 0 & 8 & 1 & 12.5 & 8 & 1 & 12.5 \\
\hline OCD & 0 & 0 & 0 & 8 & 4 & 50 & 8 & 4 & 50 \\
\hline PD & 2 & 1 & 50 & 5 & 2 & 40 & 7 & 3 \\
\hline SD & 1 & 0 & 0 & 5 & 1 & 20 & 6 & 1 & 42.3 \\
\hline Others & 1 & 0 & 0 & 14 & 0 & 0 & 15 & 0 \\
\hline
\end{tabular}

GAD, Generalized Anxiety Disorder; MADD, Mixed Anxiety and Depressive Disorder; DE, Depressive Episode; BAD, Bipolar Affective Disorder; SC, Schizophrenia ; ONOPD, Other Non Organic Psychotic Disorder; ADS, Alcohol Dependence Syndrome; DD, Dissociative Disorder; OCD, Obsessive and Compulsive Disorder ; PD, Panic Disorder; SD, Somatoform Disorder

When prevalence of melasma among different diagnostic group was compared, it was seen that prevalence was higher in anxiety disorder (Generalized anxiety disorder, Obsessive compulsive disorder and Panic Disorder) in both men and women. This was statistically significant (in men $x^{2}=0.997$, d.f. $=1, p<0.01$ : in women $x^{2}=1$, d.f.=1, $p<0.01)$ Further, among the anxiety disorders group, individuals with Generalized anxiety disorder had the highest prevalence in both genders (in men $70 \%, n=14$; in women $85.9 \%, n=69$ ). The sample size of individuals with Obsessive compulsive disorder and Panic disorder was too low to determine the statistical significance of this finding.

\section{Discussion:-}

\section{Melasma in patient and control groups}

The study validated our clinical observation that melasma is more prevalent in people with psychiatric disorders compared to general population. The results show that melasma is more commonly seen in people with anxiety disorders. In this study it was most commonly seen in individuals having Generalized anxiety disorder $(82 \%, n=69)$. Individuals with other anxiety disorders, viz Obsessive Compulsive Disorder (OCD) (50\%, $n=4)$ and Panic Disorder (PD) $(3 \%, n=42.3)$ also had high prevalence of melasma, compared to people with other psychiatric disorders. In Non-affective Psychosis group (Schizophrenia and Other Non Organic Psychotic Disorder), 14.6\% ( $n=7$ ) had melasma. It is almost absent in Depressive disorders and Bipolar disorders. Contrary to previous observations that melasma is seen usually in women in general population [4],melasma was present in large number of men (31.7\%, $\mathrm{n}=26$ ) in our patient group, though less as compared to women $(38.2 \%, \mathrm{n}=94)$. It is noteworthy that this difference was not statistically different $\left(\mathrm{x}^{2}=0.590\right.$, d.f. $\left.=1, \mathrm{p}=.289\right)$.

In the age group of $16-25$ years in the patient group, $30.8 \%(n=4)$ had melasma. This high prevalence was contrary to the previous perception[1] that melasma is an illness of middle age. Further, it was present in elderly individuals with psychiatric disorders; $33.3 \%(n=3)$ of individuals above the age of 65 years had melasma. However, sample size in both age groups was small, and further studies with large samples in these age groups need to confirm these findings.

Results have brought out interesting findings. Melasma is found to be associated most commonly with individuals having Generalized anxiety disorder and other anxiety disorders. It is much less commonly associated with 
individuals with Non affective Psychotic Disorders, and conspicuously nearly absent in patients with Bipolar Disorders and Unipolar Depressive Disorders. However, about half of the individuals with Mixed anxiety and depressive disorder $(49.1 \%, \mathrm{n}=26)$ were also found to have melasma. This observation suggests that melasma is associated with individuals who have predominantly anxiety symptoms.

From this study, it appears that melasma could be a valuable cutaneous marker for anxiety disorders in both men \& women. Being on the face, it can be easily noticed at the first sight of the individual having psychiatric symptoms and a lead towards diagnosis can be taken. Subsequent to the study, clinical observation revealed that it really helps giving a clue towards the diagnosis, and the absence of melasma in an individual with psychiatric disorder makes one think of a major psychiatric disorder like a depressive disorder or Bipolar disorder rather than an anxiety disorder.

\section{Differential diagnosis of melasma in psychiatric disorders}

Melasma should be distinguished from the pigmentation of face and exposed parts of neck and chest that people with alcohol use disorders develop. The quality of pigmentation and its distribution are different. The rare blue-grey metallic discolouration on exposed parts like face and neck after long term usage of low potency typical antipsychotics especially Chlorpromazine in high doses is also distinct from melasma. No other psychotropic medication has been reported to cause melasma like lesion on face. There is a generalized hyperpigmentation seen in pregnant women involving various parts of the body including areola, umbilicus and genitalia, apart from face[5],[6].None of our women patients were pregnant.

\section{Aetiopathogenesis of melasma}

Although exact pathogenesis is not known, it is hypothesized that, following exposure to Ultraviolet radiation or any other inducer, hyperfunctional melanocytes within involved skin produce increased amount of melanin[7]. The role of ultraviolet radiation is supported by the fading of the lesions during winter months and the distribution pattern involving sun exposed sites like face. The condition is more prevalent among people with darker complexions (skin types IV to VI), including those of Asian and Indian descent who live in areas of the world that receive highintensity ultraviolet radiation[1].Other important pathogenic factors include genetic/ethnic predisposition, especially as it relates to skin phototype and certain hormones like oestrogen and possibly progesterone. The importance of oestrogen is that the disease is most commonly seen in women, and that of progesterone is the appearance or exacerbation of the disease during pregnancy or with administration of oral contraceptives[8].Potential aggravating factors include medications like phenytoin and phototoxic drugs, and autoimmune thyroid disease. Increased expression of C-Kit and stem cell factor within lesional epidermis and dermis play a role in the hyperpigmentation of Melasma[9]. Genetic predisposition is a major factor; more than $30 \%$ had family history. Identical twins develop Melasma significantly higher than other siblings under similar conditions[10].Light to dark brown or brown gray patches with irregular borders occurs primarily in the face. Increased melanin deposition is observed in all layers of epidermis. An increased number of melanin-containing dermal macrophages (melanophages) may also be seen. The pigmentations also occur in dermis, and melasma is traditionally classified into epidermal, dermal and mixed variety [5],[6],[11].

\section{Melasma and anxiety disorders}

Melanin is formed from Tyrosine, via the action of Tyrosinase in the melanosomes of melanocytes[12]. Melanosomes are transferred from a melanocyte to a group of 36 keratinocytes called the epidermal keratin unit, to which they provide melanin. Hyperpigmented lesions usually have increased epidermal melanocyte number or activity[13].Tyrosine is also the substrate for production of catecholamines, which are implicated in anxiety disorders such as generalized anxiety disorder[14],[15].

Despite an extensive MEDLINE search, we could not find any earlier reports of association of melasma with anxiety disorders, except a case report in 1991[16]. Authors reported development of melasma in two women (35 years and 38 years old) after $8-10$ weeks of death of close relatives. Authors postulated that Melanocyte Stimulating Hormone (MSH) is controlled by Hypothalamus which in turn is influenced by deep emotions which may explain the occurrence of melasma in those individuals.

The reason for face predominantly being involved in melasma remains unexplained. One possible explanation could be the profuse vascular supply in the face and role of emotional stimuli in regulating vascular supply to some parts 
of body like face. Also, melanocytes number per unit area of epidermis influence pigmentation and this varies in different parts of the body with relatively high density on face ${ }^{[17] .}$

\section{Limitations of the study}

It is a cross sectional study; we have not considered many factors which may have influenced our findings like length and severity of the illness in each individual, and whether melasma preceded the onset of illness. This was primarily because no similar study was done in the past and our aim was to test our clinical observation.

Presence of melasma as a marker in anxiety disorders of course needs to be replicated across different ethnic populations to confirm its association. Thereafter, prospective studies may be carried out to establish a possible aetiopathological link between anxiety disorders and melasma.

\section{Conclusion:-}

This study attempted to find out the importance of melasma in patients of psychiatric disorders compared to general population and its association with any particular psychiatric disorder. Patient group had significantly higher prevalence of melasma than the control group. Among patients, people with anxiety disorders had significantly higher rates of melasma than people with other psychiatric disorders. Being on face, melasma can be easily noticed and can be a cutaneous marker for anxiety disorders.

\section{Financial support and sponsorship: Nil}

\section{Declaration of Interests: Nil}

\section{References:-}

1. Pandya AG, Guevara IL. Disorders of Hyperpigmentation. DermatolClin 2000; 18: 91-8, ix.

2. Sanchez NP, Pathak MA, Sato S, et.al. Melasma: A clinical, light microscopic ultrastructural and

3. immunofluorescence study. J Am AcadDermatol 1981; 4: 698-710.

4. World Health Organization: The ICD-10 classification of mental and behavioural disorders: Diagnostic criteria for research. Geneva, WHO, 1992.

5. Venquez M, Maldonado H, BernmannC, Sanchez JL. Melasma in men. A clinical and histologic study. Int J Dermatology 1988;27: 25-7.

6. Kovarik CL, Spielvogel RL, Kantor GR. Pigmentary disorders of the skin. In Lever's histopathology of skin $10^{\text {th }}$ Ed (ed Elder DE): 690. Lippincott Williams and Wilkins, 2009.

7. Lapeera H, Boone B, Sclapper SD, et al. Hypomelanosis and hypermelanosis. In Fitzpatrick, dermatology in general medicine $7^{\text {th }}$ Ed (edWolff K, Lowell A, Goldsmith SIK et al): 635. McGraw Hill Medicine New York, 2007.

8. Grimes PE, Yamada N, Bhawan J. Light microscopic, immunohistochemical and ultrastructural alterations in patients with melasma. Am J Dermatopathol 2005; 27: 96-101.

9. Perez-Bernal A, Munoz-perez MA, Camacho F. Management of facial hyperpigmentation. Am JClinDematol 2000; 1: 261-8.

10. Chang MW. Disorders of hyperpigmentation. In Dermatology $2^{\text {nd }}$ Ed (edBolognia JL, Jorizzo JL, Rapini RP et al): Vol 1; 939-41. Mosby Elsevier, 2008.

11. Hughes BR. Melasma occurring in twin sisters. J Am AcadDermatol 1987; 17: 841.

12. Victor FL et al. Melasma: A review. J Cutan Med Surg 2004; 8: 97.

13. Bolognia JL. Molecular advances in disorders of pigmentation. AdvDermatol 1999; 15: 141-65

14. Orlow SJ. Melanosomes are specialized members of the lysosomal lineage of organelles. J Invest Dermatol 1995; 105: 3-7.

15. Brawman-Mintzer O, Lydiard RB: Biological basis of generalized anxiety disorder. J Clin Psychiatry 1997; 58(Suppl): 16.

16. Johnson MR, Lydiard RB. The neurobiology of anxiety disorders. PsychiatrClin North Am 1995; 18: 681.

17. Wolf R, Wolf D, Tamir A, Politi Y. Melasma: A mark of stress. Br J Dermatol 1991; 125 (2): 192-3.

18. Standring S. Skin and its appendages. In Gray's Anatomy: The Anatomical basis of Clinical Practice $40^{\text {th }} \mathrm{Ed}$ (ed in chief Standring S): 148-9, 156. Churchil Livingstone, 2008. 